\title{
OTIMIZAÇÃO DA EXTRAÇÃO DE PROTEASES FÚNGICAS OBTIDAS POR FERMENTAÇÃO EM ESTADO SÓLIDO DE RESÍDUOS DE CERVEJARIA
}

\author{
SalahDin Mahmud Hasan \\ Jaqueline Pereira dos Santos ${ }^{2}$ \\ Denise Aparecida Zempulski ${ }^{1}$ \\ Mônica Lady Fiorese ${ }^{1}$ \\ Simone Damasceno Gomes ${ }^{3}$ \\ Sérgio Luiz, de Lucena ${ }^{1}$
}

\begin{abstract}
Resumo: Neste trabalho objetivou-se a otimização da extração de proteases fúngicas e a sua recuperação mediante precipitação com solvente orgânico (etanol). Para a extração foram utilizados planejamentos experimentais visando a otimização do processo por meio da avaliação da temperatura, $\mathrm{pH}$, tempo de incubação e relação sólido:solvente. A atividade proteolítica máxima de $9,00 \mathrm{U} / \mathrm{gms}$ foi obtida em pH11,8 mediante relação sólido:solvente $1: 15$ por $1 \mathrm{~h}$ de incubação a $25^{\circ} \mathrm{C}$. Os maiores valores de atividade enzimática no extrato final (clarificado) e de recuperação das proteases (92\%) por precipitação com etanol foram observados em $\mathrm{pH}$ neutro $(7,0)$.
\end{abstract}

Palavras-chave: extração, proteases fúngicas, fermentação em estado sólido, otimização.

Abstract: This work aimed to optimize the extraction process of fungal proteases and its recovery by precipitation with an organic solvent (ethanol). For extraction, experimental designs were used for the process optimization where the parameters temperature, $\mathrm{pH}$, incubation time and solid:solvent ratio were evaluated. The maximum protease activity (9.00 U/gdm) was obtained considering $\mathrm{pH} \mathrm{11.8,} \mathrm{1:15} \mathrm{of} \mathrm{solid:solvent} \mathrm{ratio,} \mathrm{for} 1 \mathrm{~h}$ of incubation at $25^{\circ} \mathrm{C}$. The higher values of enzyme activity at the final (clarified) extract and the proteases recovery (92\%) under precipitation with ethanol were observed at neutral pH (7.0).

Keywords: extraction, fungal proteases, solid state fermentation, optimization.

\footnotetext{
${ }^{1}$ Programa de Pós-graduação Stricto Sensu em Engenharia Química da Universidade Estadual do Oeste do Paraná - UNIOESTE. Rua da Faculdade, 645. Jardim Santa Maria. Toledo/ PR. CEP 85903-000. E-mail: salahdmh@gmail.com

${ }^{2}$ Programa de Pós-graduação Lato Sensu em Engenharia de Alimentos da Universidade Estadual do Oeste do Paraná - UNIOESTE. Rua da Faculdade, 645. Jardim Santa Maria. Toledo/PR. CEP 85903-000.

${ }^{3}$ Programa de Pós-graduação Stricto Sensu em Engenharia Agrícola da Universidade Estadual do Oeste do Paraná - UNIOESTE. Rua Universitária, 2069. Jardim Universitário. Cascavel/PR. CEP 85819-210.
} 


\section{INTRODUÇÃO}

$\mathrm{O}$ aumento da industrialização de alimentos trouxe ao homem sérios desafios na tentativa de manter $o$ equilíbrio ambiental. Tornou-se necessária a busca de novas tecnologias que minimizassem os impactos ambientais causados pela extração ou produção da matéria-prima, que na maioria das vezes têm efeitos poluidores devido ao volume de rejeitos que essas atividades provocam.

As pesquisas no ramo da biotecnologia têm sido de grande importância para o controle da poluição ambiental, objetivando aproveitar os resíduos industriais como substratos para o desenvolvimento de micro-organismos produtores dos mais diversos metabólitos ou produtos de interesse ecológico ou comercial, dentre eles as enzimas. Como exemplo dessas pesquisas pode-se citar a utilização dos resíduos da indústria cervejeira, como o "trub" (resíduo obtido na etapa de separação das proteínas precipitadas no "whirlpool" após a mostura) e o bagaço da cevada, os quais, devido às suas características físicoquímicas e bioquímicas, podem ser usados como substratos sólidos para a fermentação com fungos, com a consequente produção de enzimas de alto valor agregado como as proteases. Normalmente, o bagaço da cevada é aproveitado como ingrediente na ração animal, enquanto que o "trub" é descartado.

As proteases, ou enzimas proteolíticas, representam cerca de $60 \%$ do mercado industrial de enzimas e possuem um amplo espectro de aplicação como na indústria de detergentes, farmacêutica, de couro, nas indústrias alimentícias e etc. (Thanapimmethaa et al, 2012).

O "trub" apresenta elevada concentração de proteínas e matéria solúvel como carboidratos, vitaminas, sais minerais, etc. e, em função disso, apresenta bom potencial para ser usado como substrato na produção de proteases fúngicas por fermentação em estado sólido (FES).

O bagaço de cevada tem um teor proteico menor, porém suas características físicas como maior granulometria e elevado teor de fibras fazem com que o mesmo possa ser utilizado (em uma certa percentagem) como auxiliar ou suporte para o trub, pois permitiria uma melhor aeração do meio fermentativo.

Diferentes linhagens de fungos têm sido selecionadas a partir de seu habitat natural com o objetivo de se obter novas proteases, com propriedades específicas. A maioria dos pesquisadores tem buscado alternativas mais eficazes do que a fermentação submersa $(\mathrm{SmF})$ para a produção de enzimas e, neste aspecto, a fermentação em estado sólido (FES) tem apresentado algumas vantagens (Mukherjee et al, 2008).

Os processos de FES são geralmente mais simples e econômicos, e utilizam resíduos agroindustriais, tais como o farelo desengordurado de soja e farelos de trigo e arroz para a produção de enzimas, motivo pelo qual despertam interesse especial nos pesquisadores de países com abundancia de biomassa e resíduos agroindustriais, como o Brasil. As condições operacionais utilizadas na FES favorecem o crescimento de fungos filamentosos os quais na natureza crescem em substratos sólidos como pedaços de madeira, plantas, raízes e outras matérias orgânicas naturais (Mahanta et al, 2008; Zambare et al, 2011).

Portanto, as condições operacionais da FES podem estimular o micro-organismo a produzir enzimas com diferentes propriedades do que aquelas obtidas por SmF (Martins et al, 2011).

Segundo Castilho et al (2000), a eficiência de extração é um fator crítico determinante no balanço econômico da FES para a produção de enzimas. Os autores ressaltam a necessidade de estudos nessa área de modo a tornar a FES uma alternativa viável para a produção de enzimas. Citam a 
temperatura e o tipo de solvente como importantes fatores a serem investigados na extração de solutos em sólidos, além do tempo de incubação.

Assim, tendo em vista a alta aplicabilidade das proteases e a quantidade limitada de referências que tratam do aproveitamento de resíduos de cervejaria para esse fim, o objetivo deste trabalho foi o estudo e a otimização do processo de extração de proteases fúngicas, obtidas de fermentação em estado sólido de resíduos de cervejaria ("trub"e bagaço de cevada), utilizando planejamentos fatoriais e o estudo da recuperação das proteases dos extratos brutos mediante precipitação com solvente orgânico (etanol).

\section{MATERIAIS E MÉTODOS}

\subsection{MATERIAL}

Para a produção e os ensaios de extração de protease foi utilizada amostra de trub fermentado seco. A fermentação em estado sólido do trub foi realizada utilizando como micro-organismo um fungo isolado do próprio substrato e identificado como Aspergillussp., uma vez que o melhor valor observado de produtividade em termos de obtenção da protease foi para este fungo.

A amostra de trub fermentado seco continha, além das proteases, do trub e do micélio do fungo, outras substâncias como: bagaço da cevada (usado como auxiliar ou suporte), umidade e nutrientes $\left(\mathrm{K}_{2} \mathrm{HPO}_{4}, \mathrm{NaNO}_{3}\right.$, URÉIA, $\mathrm{MgSO}_{4}, \mathrm{ZnSO}_{4}, \mathrm{FeSO}_{4}, \mathrm{MnSO}_{4}$, $\mathrm{CuSO}_{4}$ ) adicionados para o crescimento do fungo. Para a FES foram usados (em base seca) $29 \mathrm{~g}$ de trub, $9 \mathrm{~g}$ de bagaço e $2 \mathrm{~g}$ de sais, para uma umidade inicial ajustada em $50 \%$.

O trub e o bagaço de cevada foram coletados em uma indústria cervejaria local (Toledo-PR) em quantidade suficiente para a realização de todos os experimentos. Para a correção do $\mathrm{pH}$ das soluções no processo de extração foram utilizadas as seguintes soluções tamponantes: tampão acetato ( $\mathrm{pH} 4,5)$, tampão fosfato de sódio ( $\mathrm{pH}$ $6,2 ; 6,5 ; 7,0$ e 9,0$)$, tampão glicina $(\mathrm{pH}$ 9,0 ) e tampão Ringer (pH 11,8, contendo $\mathrm{Na}_{2} \mathrm{HPO}_{4}$ e $\mathrm{NaOH}$ ).

\subsection{EXTRAÇÃO DAS ENZIMAS}

A avaliação das condições de extração foi feita por planejamento estatístico experimental do tipo "Planejamento Fatorial Fracionário 24" (Barros Neto et al, 2010). Neste tipo de planejamento fatorial foram avaliados os efeitos de 4 variáveis sobre a resposta (atividade enzimática, AE), utilizando-se 2 níveis $(-1$ e +1$)$ para cada variável, resultando em 8 ensaios acrescidos de triplicata no ponto central (nível 0) para a estimativa do erro experimental (Montgomery, 1997).

As 4 variáveis estudadas foram: temperatura $(\mathrm{T}), \quad \mathrm{pH}, \quad$ relação sólido:solvente (R) e tempo de incubação (t), cujos níveis (valores codificados) e valores reais encontram-se na Tabela 1 .

O programa computacional Statistica v. 8.0 (StatSoft Inc., Tulsa, USA) foi utilizado para calcular os efeitos principais das variáveis e suas interações, bem como os dados relativos a análise de variância (ANOVA). Os efeitos são descritos como a diferença entre a resposta média no nível superior (+1) e a resposta média no nível inferior (-1) de uma determinada variável. Para se determinar a influência de um efeito no sistema, compara-se a magnitude do valor deste efeito ao erro experimental.

A extração das proteases foi realizada em frascos Erlenmeyer de 250 $\mathrm{mL}$ a partir de uma amostra de trub fermentado considerando a relação sólido:solvente para realizar a adição da solução tamponante. Depois de adicionada a solução tamponante, a amostra foi colocada em um banho termostatizado com controle de temperatura, onde ficaram incubadas sob agitação.

A relação sólido:solvente, o $\mathrm{pH}$ (adição da solução tamponante), a temperatura e o tempo de incubação sob agitação foram utilizados conforme 
especificado para cada ensaio no planejamento experimental. Ao final da extração, os extratos brutos foram filtrados em papel de filtro, com posterior centrifugação. As amostras de extrato bruto foram posteriormente armazenadas em tubos de ensaio e conservadas em geladeira.

\subsection{RECUPERAÇÃO DAS PROTEA- SES}

As proteases foram recuperadas a partir do extrato bruto usando o método de precipitação com solvente orgânico. No caso, foi adicionado gradualmente, ao extrato bruto centrifugado, etanol p.A. até uma concentração $70 \%$.

A precipitação foi realizada em tubos de ensaio a $0^{\circ} \mathrm{C}$, com o auxílio de um banho de gelo, sendo o etanol e o extrato bruto pré-resfriados em geladeira a $4^{\circ} \mathrm{C}$. A adição lenta e gradual do etanol foi feita sobre o extrato bruto sob agitação branda e constante, sendo esta operação realizada em $1,5 \mathrm{~h}$.

Após a precipitação das proteases, os respectivos precipitados foram separados por centrifugação $(5000 \mathrm{~g}$, por 30 min) onde, após o descarte do sobrenadante, foram ressolubilizados com o tampão apropriado, para subsequente análise imediata da atividade enzimática. A seguir, as amostras foram seladas e conservadas em geladeira a $4^{\circ} \mathrm{C}$.

\subsection{MÉTODOS ANALÍTICOS}

A análise de atividade enzimática (AE) foi realizada conforme método adaptado de Germano et al (2003), utilizando a albumina de soro bovino (BSA) como substrato.

Os resultados de atividade enzimática foram expressos em unidades por grama de matéria seca ou U/gms, onde $\mathrm{U}$ foi definido como a quantidade de enzima que produziu uma diferença de absorbância (em relação ao controle) durante $1 \mathrm{~h}$ de incubação à $45^{\circ} \mathrm{C}$ para um grama de meio fermentado em base seca.

A umidade das amostras do meio fermentado foi determinada por método gravimétrico baseado na perda de massa após secagem em estufa, à temperatura de $105^{\circ} \mathrm{C}$, por $3 \mathrm{~h}$ ou mais, até massa constante, medido em balança analítica após resfriamento das amostras em dessecador (AACC, 1983).

\section{RESULTADOS E DISCUSSÃO}

\subsection{EXTRAÇÃO DAS PROTEASES}

A Tabela 1 mostra os resultados obtidos de atividade enzimática após a extração das proteases, utilizando-se o planejamento fatorial fracionário $2^{4-1}$. Os valores reais das variáveis utilizados nos ensaios encontram-se especificados na Tabela 1.

$\mathrm{Na}$ Tabela 2 podem ser observados os efeitos de cada variável sobre a resposta (AE), os efeitos das interações entre as variáveis, o erro puro associado a cada efeito, o valor da probabilidade (p) do efeito influenciar a resposta no intervalo de confiança de 95\% e o coeficiente para cada variável a ser usada no modelo empírico. $\mathrm{O}$ intercepto é o termo independente usado no modelo.

A estatística " $\mathrm{t}^{2}$ " representa a razão entre o valor estimado do efeito e seu erro padrão, e constitui o valor do efeito padronizado. Deste modo, pode-se afirmar que as variáveis $\mathrm{pH}$ e $\mathrm{R}$ influenciaram a $\mathrm{AE}$ e que o aumento do $\mathrm{pH}$ e de $\mathrm{R}$ promoveram o aumento na atividade enzimática (efeito positivo). Por outro lado, a interação conjugada dos fatores $\mathrm{T}$ e $\mathrm{pH}$ e dos fatores $\mathrm{T}$ e $\mathrm{R}$ promoveram a diminuição na atividade enzimática (efeito negativo).

A equação (1) é um modelo linear empírico, obtido mediante os coeficientes obtidos e pode ser usada para descrever de forma aproximada os resultados de AE em termos dos efeitos significativos do $\mathrm{pH}$ e $\mathrm{R}$ e das interações $\mathrm{T}$ e $\mathrm{pH}$ e $\mathrm{T}$ e $\mathrm{R}$ (com coeficiente de determinação $\mathrm{R}^{2}$ de $98,1 \%)$.

$\mathrm{AE}=2,784+0,936 \cdot \mathrm{pH}+0,516 \cdot \mathrm{R}-$ 0,556.T.pH - 0,506.T.R 
A Figura 1 apresenta a superfície de resposta obtida para o processo considerando a $\mathrm{AE}$ como resposta, de acordo com a equação (1).Para avaliar se a equação (1) ajusta de forma satisfatória os resultados de $\mathrm{AE}$ com os valores codificados das variáveis, foi feita a análise de variância (ANOVA) do modelo (Tabela 3). Como o valor de $\mathrm{F}_{\text {calculado }}=22,26$ forneceu valor maior que o $\mathrm{F}_{\text {tabelado }}=8,89$ para $\mathrm{o}$ modelo e $\mathrm{F}_{\text {calculado }}=$ 1,16 forneceu valor menor que o $\mathrm{F}_{\text {tabelado }}=$ 18,51 para a falta de ajuste, pode-se afirmar que o respectivo modelo matemático, descrito pela equação (1), é válido no intervalo de confiança de $95 \%$, podendo ser usado para avaliar o resultado de $\mathrm{AE}$ em termos de $\mathrm{pH}, \mathrm{R}$, interação $\mathrm{T}$ e pH e T e R. Tabela 1: Matriz do planejamento fatorial fracionário $2^{4-1}$ com as variáveis
codificadas e reais e os resultados obtidos de atividade enzimática (AE).

\begin{tabular}{lccccc}
\hline Ensaio & $\mathrm{T}\left({ }^{\circ} \mathrm{C}\right)$ & $\mathrm{pH}$ & $\mathrm{R}$ & $\mathrm{t}$ & $\begin{array}{c}\mathrm{AE} \\
(\mathrm{U} / \mathrm{gms})\end{array}$ \\
\hline 1 & $-1(25)$ & $-1(4,5)$ & $-1(1: 5)$ & $-1(1)$ & 0,84 \\
2 & $1(55)$ & $-1(4,5)$ & $-1(1: 5)$ & $1(3)$ & 2,36 \\
3 & $-1(25)$ & $1(9,0)$ & $-1(1: 5)$ & $1(3)$ & 2,56 \\
4 & $1(55)$ & $1(9,0)$ & $-1(1: 5)$ & $-1(1)$ & 3,07 \\
5 & $-1(25)$ & $-1(4,5)$ & $1(1: 15)$ & $1(3)$ & 1,62 \\
6 & $1(55)$ & $-1(4,5)$ & $1(1: 15)$ & $-1(1)$ & 2,33 \\
7 & $-1(25)$ & $1(9,0)$ & $1(1: 15)$ & $-1(1)$ & 5,87 \\
8 & $1(55)$ & $1(9,0)$ & $1(1: 15)$ & $1(3)$ & 3,14 \\
9 & $0(40)$ & $0(6,5)$ & $0(1: 10)$ & $0(2)$ & 3,24 \\
10 & $0(40)$ & $0(6,5)$ & $0(1: 10)$ & $0(2)$ & 2,63 \\
11 & $0(40)$ & $0(6,5)$ & $0(1: 10)$ & $0(2)$ & 2,97 \\
\hline
\end{tabular}

Tabela 2: Estimativa dos efeitos sobre AE das proteases, para intervalo de confiança de $95 \%$, obtida para o planejamento fatorial fracionário $2^{4-1}\left(R^{2}=0,9810\right)$.

\begin{tabular}{lccccc}
\hline Variável & Efeito & Erro puro & $\mathrm{t}^{2}$ & p-valor & Coeficiente \\
\hline $\mathrm{T}$ & 0,0025 & 0,21614 & 0,01157 & 0,991821 & 0,001250 \\
$\boldsymbol{p} \boldsymbol{H}$ & $\mathbf{1 , 8 7 2 5}$ & $\mathbf{0 , 2 1 6 1 4}$ & $\mathbf{8 , 6 6 3 3 5}$ & $\mathbf{0 , 0 1 3 0 6 3}$ & $\mathbf{0 , 9 3 6 2 5 0}$ \\
$\boldsymbol{R}$ & $\mathbf{1 , 0 3 2 5}$ & $\mathbf{0 , 2 1 6 1 4}$ & $\mathbf{4 , 7 7 6 9 9}$ & $\mathbf{0 , 0 4 1 1 3 7}$ & $\mathbf{0 , 5 1 6 2 5 0}$ \\
$\mathrm{t}$ & $-0,6075$ & 0,21614 & $-2,81067$ & 0,106704 & $-0,303750$ \\
$\boldsymbol{T} \boldsymbol{x} \boldsymbol{p H}$ & $\mathbf{- 1 , 1 1 2 5}$ & $\mathbf{0 , 2 1 6 1 4}$ & $\mathbf{- 5 , 1 4 7 1 2}$ & $\mathbf{0 , 0 3 5 7 3 5}$ & $\mathbf{- 0 , 5 5 6 2 5 0}$ \\
$\boldsymbol{T} \boldsymbol{x} \boldsymbol{R}$ & $\mathbf{- 1 , 0 1 2 5}$ & $\mathbf{0 , 2 1 6 1 4}$ & $\mathbf{- 4 , 6 8 4 4 6}$ & $\mathbf{0 , 0 4 2 6 7 4}$ & $\mathbf{- 0 , 5 0 6 2 5 0}$ \\
$\mathrm{T}$ x t & 0,6575 & 0,21614 & 3,04200 & 0,093202 & 0,328750 \\
Intercepto & $\mathbf{2 , 7 8 4 5}$ & $\mathbf{0 , 0 9 2 1 6}$ & $\mathbf{3 0 , 2 1 3 4 1}$ & $\mathbf{0 , 0 0 1 0 9 4}$ & $\mathbf{2 , 7 8 4 5 4 5}$ \\
\hline
\end{tabular}

Os valores em negrito e itálico evidenciam as variáveis significativas no intervalo de confiança de $95 \%$ (p-valor $<0,05$ ).

Como foi observado que o aumento do valor do $\mathrm{pH}$ e do $\mathrm{R}$ influenciam positivamente a atividade enzimática, resolveu-se realizar novos ensaios com valores maiores de $\mathrm{pH}$ e $\mathrm{R}$ para avaliar o efeito deste aumento sobre a AE. A Tabela 4 mostra os níveis e os valores reais usados para as variáveis $\mathrm{pH}$ e R, para o novo planejamento.
Este novo planejamento, chamado de planejamento composto central consiste de um fatorial completo $2 \mathrm{k}$ com replicatas no ponto central e dois pontos sobre o eixo de cada variável a uma distância $\pm \alpha$ do ponto central (planejamento estrela), conforme teoria descrita por Khuri \& Cornell (1987). 
As variáveis estudadas foram o $\mathrm{pH}$ e a relação sólido:solvente (R). Assim, o planejamento composto central, descrito na Tabela 5, tem um planejamento completo $2^{2}$ representado pelos ensaios 1 a 4 (com níveis -1 e +1 ) para a estimativa da porção linear do modelo matemático quadrático, uma triplicata no ponto central (com nível 0) representada pelos ensaios 5 a 7 (para a estimativa do erro experimental) e 4 ensaios para o planejamento estrela representados pelos níveis $\alpha=-1,414$ e $\alpha$ $=+1,414$ para a estimativa da porção não linear do modelo empírico quadrático, de maior abrangência que o linear (Barros Neto et al, 2010).

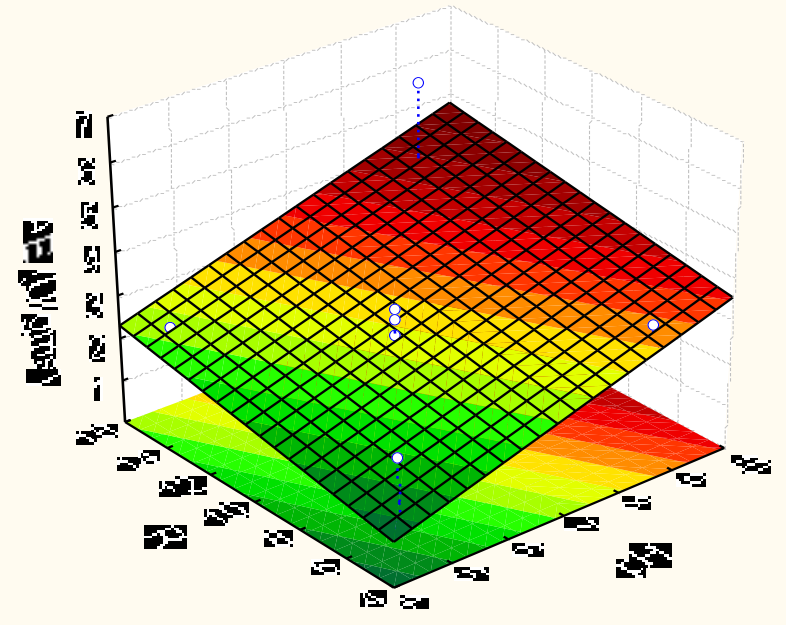

Figura 1: Superfície de resposta para a AE das proteases em função da relação sólido:solvente (R) e do $\mathrm{pH}$, obtida para o planejamento fatorial fracionário $2^{4-1}$.

Tabela 3: Análise de variância do modelo linear da AE, com intervalo de confiança de $95 \%$, obtida para o planejamento fatorial fracionário $2^{4-1}$

\begin{tabular}{lcccc}
\hline Causa de variação & SQ & GL & MQ & F \\
\hline Modelo & 15,273 & 7 & 2,182 & 22,26 \\
Erro Total & 0,295 & 3 & 0,098 & \\
\hline Falta de Ajuste & 0,108 & 1 & 0,108 & 1,16 \\
Erro puro & 0,187 & 2 & 0,093 & \\
\hline Total & 15,568 & 10 & &
\end{tabular}

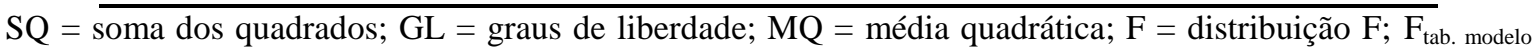
$(0,05 ; 7 ; 3)=8,89 ; \mathrm{F}_{\text {tab. falta de ajuste }}(0,05 ; 1 ; 2)=18,51$

Como o melhor resultado de $\mathrm{AE}$ no planejamento fracionário $2^{4-1}$ (Tabela 1) foi obtido no ensaio $7(\mathrm{AE}=5,87$ U/gms), que corresponde ao $\mathrm{pH}$ no nível $+1(9,0)$, R no nível +1 (1:15), T no nível $-1 \quad\left(25^{\circ} \mathrm{C}\right)$ e $\mathrm{t}$ no nível $-1 \quad(1 \mathrm{~h})$, considerou-se no novo planejamento o ponto central, nível 0 , como sendo $\mathrm{pH}=$ 9,0 e $\mathrm{R}=1: 15$ (Tabela 4).

As demais variáveis ( $\mathrm{T}$ e $\mathrm{t}$ ), não significativas no planejamento fracionário $2^{4-1}$,foram mantidas nos mesmos níveis do ensaio 7 do planejamento fracionário $2^{4-1}$, ou seja, $\mathrm{T}=55^{\circ} \mathrm{C}$ e $\mathrm{t}=1 \mathrm{~h}$. Observa-se na Tabela 5 que a maioria dos valores de $\mathrm{AE}$ foram mais elevados que aqueles obtidos no planejamento fatorial fracionário $2^{4-1}$ (Tabela 1), indicando que os níveis das variáveis foram escolhidos corretamente. Os valores obtidos para os efeitos principais e de interação das variáveis $\mathrm{pH}$ 
e $\mathrm{R}$ de ordem linear (L) e quadrática (Q) são apresentados na Tabela 6, para o intervalo de confiança de 95\%. Observase que, além do intercepto, apenas a variável $\mathrm{pH}$ linear foi significativa no intervalo de confiança de $95 \%$, ou seja, o aumento linear do $\mathrm{pH}$ influenciou positivamente o resultado de AE.

A Figura 2 apresenta a superfície de resposta obtida para o processo. Observa-se que a $\mathrm{AE}$ aumenta com o $\mathrm{pH}$, porém diminui com $\mathrm{R}$, de forma menos pronunciada uma vez que esta variável não se mostrou significativa nointervalo de $95 \%$ de confiança.Foi feita a análise de variância (ANOVA) do modelo (Tabela 7). Como o valor de $\mathrm{F}_{\text {calculado }}=$ 1,47 resultou menor que o $F_{\text {tabelado }}=5,05$ para o modelo, pode-se afirmar que o modelo matemático, descrito por uma equação quadrática, não é válido no intervalo de confiança de $95 \%$, não podendo ser usado para avaliar o resultado de AE. Maiores valores de atividade enzimática (ensaios 2 e 10 ) foram obtidos com o aumento do $\mathrm{pH}$, indicando que a protease em questão é do tipo alcalina, pois é mais ativa na faixa de $\mathrm{pH}$ alcalino.

Tabela 4: Especificação dos níveis das variáveis do planejamento composto central

\begin{tabular}{lccccc}
\hline & \multicolumn{5}{c}{ Níveis } \\
\cline { 2 - 6 } Variável & $-1,414$ & -1 & 0 & +1 & $+1,414$ \\
\hline $\mathrm{pH}$ & 6,2 & 7,0 & 9,0 & 11,0 & 11,8 \\
$\mathrm{R}$ & $1: 10,8$ & $1: 12$ & $1: 15$ & $1: 18$ & $1: 19,3$ \\
\hline
\end{tabular}

Tabela 5: Matriz do planejamento composto centralcom as variáveis codificadas e resultados obtidos de atividade enzimática (AE)

\begin{tabular}{lccc}
\hline Ensaio & $\mathrm{pH}$ & $\mathrm{R}$ & $\begin{array}{c}\mathrm{AE} \\
(\mathrm{U} / \mathrm{gms})\end{array}$ \\
\hline 1 & $-1(7,0)$ & $-1(1: 12)$ & 7,83 \\
2 & $+1(11,0)$ & $-1(1: 12)$ & 8,76 \\
3 & $-1(7,0)$ & $+1(1: 18)$ & 4,22 \\
4 & $+1(11,0)$ & $+1(1: 18)$ & 7,04 \\
5 & $0(9,0)$ & $0(1: 15)$ & 5,09 \\
6 & $0(9,0)$ & $0(1: 15)$ & 6,47 \\
7 & $0(9,0)$ & $0(1: 15)$ & 5,09 \\
8 & $-1,414(6,2)$ & $0(1: 15)$ & 3,52 \\
9 & $0(9,0)$ & $-1,414(1: 10,8)$ & 5,35 \\
10 & $+1,414(11,8)$ & $0(1: 15)$ & 9,00 \\
11 & $0(9,0)$ & $+1,414(1: 19,3)$ & 8,06 \\
\hline
\end{tabular}

Tabela 6: Estimativa dos efeitos sobre AE, para intervalo de confiança de $95 \%$, obtida para o planejamento composto central $\left(R^{2}=0,886\right)$.

\begin{tabular}{lccccc}
\hline Variável & Efeito & Erro puro & $\mathrm{t}^{2}$ & $\mathrm{p}$-valor & Coeficiente \\
\hline $\boldsymbol{p H}(\boldsymbol{L})$ & $\mathbf{2 , 8 7}$ & $\mathbf{0 , 5 6}$ & $\mathbf{5 , 1 0}$ & $\mathbf{0 , 0 3 6 3}$ & $\mathbf{1 , 4 3}$ \\
$\mathrm{pH}(\mathrm{Q})$ & 0,95 & 0,67 & 1,41 & 0,2922 & 0,47 \\
$\mathrm{R}(\mathrm{L})$ & $-0,37$ & 0,56 & $-0,66$ & 0,5746 & $-0,19$ \\
$\mathrm{R}(\mathrm{Q})$ & 1,39 & 0,67 & 2,08 & 0,1729 & 0,69 \\
pHxR & 0,94 & 0,79 & 1,18 & 0,3574 & 0,47 \\
Intercepto & $\mathbf{5 , 5 5}$ & $\mathbf{0 , 4 6}$ & $\mathbf{1 2 , 0 6}$ & $\mathbf{0 , 0 0 6 8}$ & $\mathbf{5 , 5 5}$ \\
\hline
\end{tabular}


Em trabalho realizado anteriormente para caracterizar a enzima definiu-se que os melhores parâmetros selecionados para a determinação analítica da atividade enzimática da protease (caracterização cinética) obtida por fermentação em estado sólido de Aspergillussp. Em trub foram: temperatura de $50^{\circ} \mathrm{C}$, concentração de solução de BSA de $0,5 \%$ (substrato), tempo de incubação de $20 \mathrm{~min}$ e utilização do tampão fosfato $0,2 \mathrm{M}(\mathrm{pH} 7,0)$. Em relação ao $\mathrm{pH}$ observou-se que a enzima se mantinha estável numa ampla faixa
$(\mathrm{pH} \quad 6 \quad$ a 10). Estes valores da caracterização cinética da enzima estão próximos aos encontrados no estudo da extração, indicando que a enzima é mais ativa em $\mathrm{pH}$ alcalino e estável numa faixa mais extensa de $\mathrm{pH}$ (6 a 10).

Para efeito de comparação com a literatura, a Tabela 8 apresenta algumas referências onde se pode observar os valores de $\mathrm{pH}$ onde as proteases alcalinas são mais ativa e os valores de $\mathrm{pH}$ onde as enzimas são mais estáveis.

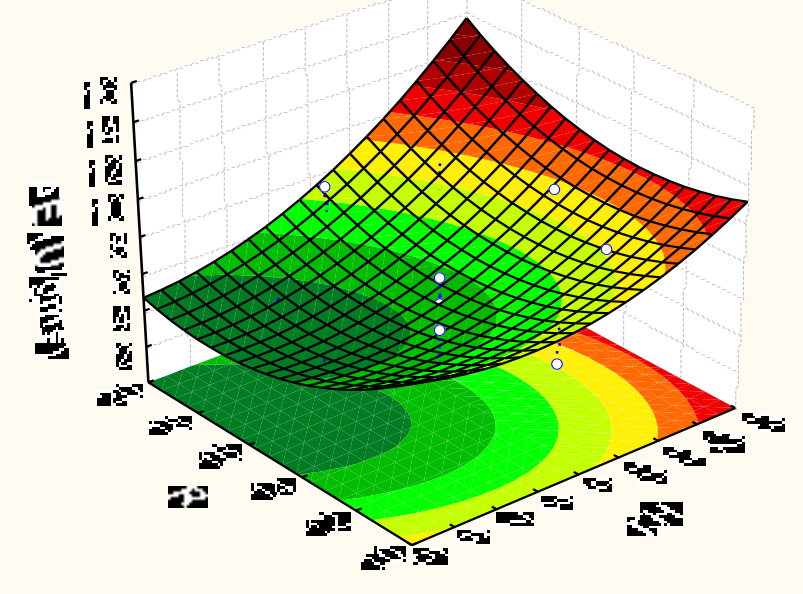

Figura 2: Superfície de resposta para a $\mathrm{AE}$ das proteases em função da relação sólido:solvente $(\mathrm{R})$ e do $\mathrm{pH}$, obtida para o planejamento composto central.

Tabela 7: Análise de variância do modelo quadrático da AE, com intervalo de confiança de $95 \%$, obtida para o planejamento composto central

\begin{tabular}{lcccc}
\hline Causa de variação & SQ & GL & MQ & F \\
\hline Modelo & 20,902 & 5 & 4,18 & 1,47 \\
Erro Total & 14,224 & 5 & 2,84 & \\
\hline Falta de Ajuste & 12,955 & 3 & 4,32 & \\
Erro puro & 1,269 & 2 & 0,63 & \\
\hline
\end{tabular}

Total $35,126 \quad 10$

SQ = soma dos quadrados; GL = graus de liberdade; MQ = média quadrática; $\mathrm{F}=$ distribuição F; Para o modelo: $\mathrm{F}_{\text {tabelado }}:(0,95 ; 5 ; 5)=5,05$

\subsection{RECUPERAÇÃO DAS PROTEASES}

Foram utilizadas amostras de extratos brutos com diferentes valores de pH para os ensaios de precipitação das ENGEVISTA, V. 16, n. 2, p.244-254, Junho 2014 proteases com solvente orgânico (etanol com concentração final de $70 \%)$. A Tabela 9 mostra os resultados de atividade enzimática dos extratos brutos (em diferentes pHs) e dos respectivos extratos clarificados obtidos após a precipitação com etanol.Os valores de $\mathrm{AE}$ 
dos extratos foram expressos em $\mathrm{U} / \mathrm{mL}$. Apesar do extrato bruto com $\mathrm{pH}$ 7,0 ter apresentado valor de atividade enzimática $(2,5 \mathrm{U} / \mathrm{mL})$ inferior aos dos demais ensaios, observou-se que a recuperação das proteases por precipitação com solvente orgânico (etanol 70\%) foi melhor conduzida em $\mathrm{pH}$ neutro $(7,0)$ onde, além de se obter maior valor de atividade enzimática no extrato final (clarificado),

observou-se consequentemente um maior valor de recuperação da protease $(92,0 \%)$. Observa-se o maior valor de $\mathrm{AE}$ do extrato clarificado no $\mathrm{pH} 7,0$, com consequente maior eficiência de recuperação neste $\mathrm{pH}$. Assim, a extração pode ser efetuada em meio com tampão pH 7,0 $(\mathrm{R}=1: 12)$, com subsequente recuperação por precipitação com etanol.

Tabela 8: Valores de $\mathrm{pH}$ encontrados na literatura para as proteases alcalinas obtidas por FES de diferentes micro-organismos em diferentes substratos

\begin{tabular}{lccccc}
\hline Micro-organismo & $\begin{array}{c}\text { Substrato usado } \\
\text { na FES }\end{array}$ & $\begin{array}{c}\mathrm{pH} \text { mais } \\
\text { estável }\end{array}$ & $\begin{array}{c}\mathrm{pH} \\
\text { mais } \\
\text { ativo }\end{array}$ & $\begin{array}{c}\text { Tampão } \\
\text { usado na } \\
\text { extração }\end{array}$ & Referência \\
\hline Penicilliumsp. & farelo de trigo & - & 9,0 & $\begin{array}{c}\text { borato (pH } \\
9,0)\end{array}$ & $\begin{array}{c}\text { Agrawal et al } \\
\text { (2003) }\end{array}$ \\
\hline Bacillus sp. & farelo de trigo & - & 10,0 & $\begin{array}{c}\text { carbonato } \\
\text { (pH 10,0) }\end{array}$ & $\begin{array}{c}\text { Uyar\&Baysal } \\
\text { (2003) }\end{array}$ \\
\hline Aspergillus tamarii & $\begin{array}{c}\text { ágar leite } \\
\text { desnatado }\end{array}$ & $\begin{array}{c}8,0 \mathrm{a} \\
11,0\end{array}$ & $\begin{array}{c}8,0 \mathrm{a} \\
9,0\end{array}$ & $\begin{array}{c}\text { Tris-HCl } \\
\text { (pH 8,0) }\end{array}$ & $\begin{array}{c}\text { Dayanandan et } \\
\text { al (2003) }\end{array}$ \\
\hline Penicillium sp. & $\begin{array}{c}\text { torta de soja } \\
\text { desengordurada }\end{array}$ & 6,0 a 9,0 & 6,5 & $\begin{array}{c}\text { citrato- } \\
\text { fosfato (pH } \\
6,5)\end{array}$ & $\begin{array}{c}\text { Germano et al } \\
\text { (2003) }\end{array}$ \\
\hline Aspergillus parasiticus & farelo de trigo & $6,0 \mathrm{a}$ & 8,0 & $\begin{array}{c}\text { diversos } \\
\text { (pH4,0 a } \\
10,0\end{array}$ & $\begin{array}{c}\text { Tunga et al } \\
\text { (2003) }\end{array}$ \\
\hline Beauveria felina & farelo de trigo & - & 7,0 & $\begin{array}{c}\text { carbonato } \\
\text { (pH 10,0) }\end{array}$ & $\begin{array}{c}\text { Agrawal et al } \\
\text { (2005) }\end{array}$ \\
\hline Bacillussubtilis & casca de batata & 8,0 a 9,0 & 8,0 & $\begin{array}{c}\text { fosfato } \\
\text { (pH 8,0) }\end{array}$ & $\begin{array}{c}\text { Mukherjee et al } \\
\text { (2008) }\end{array}$ \\
\hline Pseudomonasaeruginosa & $\begin{array}{c}\text { semente de } \\
\text { jatropha }\end{array}$ & 6,0 a 7,5 & 6,0 & $\begin{array}{c}\text { fosfato } \\
\text { (pH 7,0) }\end{array}$ & $\begin{array}{c}\text { Mahanta et al } \\
\text { (2008) }\end{array}$ \\
\hline Pseudomonasaeruginosa & farelo de soja e & 7,0 a 9,0 & 8,0 & $\begin{array}{l}\text { tris-HCl } \\
\text { (pH 8,0) }\end{array}$ & $\begin{array}{c}\text { Zambare et al } \\
\text { (2011) }\end{array}$ \\
\hline
\end{tabular}

Tabela 9: Atividade enzimática dos extratos brutos e dos extratos clarificados obtidos após a precipitação com etanol

\begin{tabular}{lccc}
\hline \multirow{2}{*}{$\begin{array}{l}\mathrm{pH} \text { do extrato } \\
\text { bruto }\end{array}$} & \multicolumn{2}{c}{$\mathrm{AE}(\mathrm{U} / \mathrm{mL})$} & \multirow{2}{*}{$\%$ recuperação } \\
\cline { 2 - 3 } & Extrato bruto & Extrato clarificado & \\
\hline 4,2 & 3,6 & 2,2 & 61,1 \\
5,0 & 3,1 & 2,2 & 71,0 \\
7,0 & 2,5 & 2,3 & 92,0 \\
9,0 & 3,6 & 1,8 & 50,0 \\
\hline
\end{tabular}

\section{CONCLUSÃO}

Para a extração das proteases, os resultados obtidos nos planejamentos experimentais indicaram que a atividade ENGEVISTA, V. 16, n. 2, p.244-254, Junho 2014 enzimática (AE) é influenciada positivamente pelo aumento do $\mathrm{pH}$. Foi observado que a recuperação dessas enzimas por precipitação com etanol foi melhor conduzida em $\mathrm{pH}$ neutro $(7,0)$ 
onde, além de se obter maior valor de atividade enzimática no extrato final (clarificado),observou-se consequentemente um maior valor de recuperação da protease $(92,0 \%)$.

\section{AGRADECIMENTOS}

Os autores agradecem ao Conselho Nacional de Desenvolvimento Científico e Tecnológico (CNPq) pelo auxílio financeiro.

\section{REFERÊNCIAS}

AACC - American Association of Cereal Chemists. 1983. Approved Methods of the American Association of Cereal Chemists. St. Paul-Minnesota, 8th ed., v.1-2.

AGRAWAL, D.; PATIDAR, P.; BANERJEE \& T.; PATIL, S. 2003.Production of alkaline protease by Penicillium sp. under SSF conditions and its application to soy protein hydrolysis.Process Biochem., p.1-6.

AGRAWAL, D.; PATIDAR, P.; BANERJEE \& T.; PATIL, S. 2005.Alkaline protease production by a soil isolate of Beauveriafelina under SSF condition: parameter optimization and application to soy protein hydrolysis. ProcessBiochem., v.40, p.1131-1136.

BARROS Neto, B.; SCARMINIO, I.S. \&BRUNS, R.E. 2010. Como fazer experimentos - Aplicações na ciência e na indústria. Porto Alegre: Editora Bookman, 4a.ed., 414p.

CASTILHO, L.R.; MEDRONHO, R.A. \& ALVES, T.L.M. 2000. Production and extraction of pectinases obtained by solid state fermentation of agroindustrial residues with Aspergillusniger. Bior.Technol., v.71, p.45-50.

DAYANANDAN, A.; KANAGARAJ, J.; SOUNDERRAJ, L.; GOVINDARAJU,
$\mathrm{R}$. \&RAJKUMAR,

G.S.

2003.Application of an alkaline protease in leather processing: an ecofriendly approach. J. Cleaner Prod., v.11, p.533536.

GERMANO S.; PANDEY, A.; OSAKU, C.A.; ROCHA, S.N. \&SOCCOL, C.R. 2003. Characterization and stability of proteases from Penicillium sp. produced by solid-state fermentation.Enz.Microbial Technol., n.32, p.246-251.

KHURI, A. \& CORNELL, J.A. 1987.Response surface: designs and analyses.American Society for Quality Control.

MAHANTA, N.; GUPTA, A.; KHARE, S.K. 2008.Production of protease and lipase by solvent tolerant Pseudomonas aeruginosaPse $\mathrm{A}$ in solid-state fermentation using Jatrophacurcas seed cake as substrate.Bior. Technol., 99, p.1729-1735.

MARTINS, S. A.; SOLANGE, I.;MUSSATTO, A.; MARTÍNEZAVILA, G. B.; MONTAÑEZ-SAENZ, J. C.; CRISTÓBAL, N.; AGUILAR, B.; TEIXEIRA, J.A. 2011. Bioactive phenolic compounds: Production and extraction by solid-state fermentation. A review.Biotech.Adv., 29, p.365-373.

MONTGOMERY, D.C. 1997. Design and analysis of experiments. IE-Wiley Press, New York.

MUKHERJEE, A.K.; ADHIKARI, H.; RAI, S.K. 2008. Production of alkaline protease by a thermophilicBacillus subtilis under solid-state fermentation (SSF) condition using Imperata cylindrical grass and potato peel as lowcost medium: Characterization and application of enzyme in detergent formulation. Biochem.Eng. Journal., 39, p.353-361. 
TITAPIWATANAKUNC, B.; SRINOPHAKUN, P. 2012. Value added waste of Jatrophacurcas residue: Optimization of protease production in solid state fermentation by Taguchi DOE methodology. Ind. Crops Prod., 37, p.15.

TUNGA, R.; SHRIVASTAVA, B. \& BANERJEE, R. 2003.Purification and characterization of a protease from solid state cultures of Aspergillusparasiticus.Proc.Biochem., n.38, p.1553-1558.

UYAR, F. \&BAYSAL, Z. 2003.Production and optimization of process parameters for alkaline protease production by a newly isolated Bacillus sp. under solid state fermentation.Proc. Biochem., p.1-6.

ZAMBARE, V.; NILEGAONKAR, S.; KANEKAR, P. 2011. A novel extracellular protease from Pseudomonas aeruginosa MCM B-327: enzyme production and its partial characterization. New Biotech., 28-2, p.173-181. 